\title{
THE ROLE OF TUTORS IN MATHEMATICAL NOTICING IN AN UNDERGRADUATE QUANTITATIVE LITERACY COURSE: CONCEPTUALISING THE TIME VALUE OF MONEY
}

\section{Mhakure}

\author{
Academic Development Programmes, Centre for Higher Education \\ University of Cape Town \\ Cape Town, South Africa \\ e-mail: duncan.mhakure@uct.ac.za / https://orcid.org/0000-0001-6776-6244
}

\section{ABSTRACT}

In the past two decades many studies have been carried out on the tutor-student interactions in higher education courses, particularly in undergraduate courses with the foci on exploring students' deep learning. However, few studies have focussed on the role of tutors' in "mathematical noticing" during classroom activities. Therefore, this study using the topic on time value of money seeks to explore the roles tutors play during mathematical noticing when facilitating a Quantitative Literacy undergraduate course. Data was collected from transcriptions of two videorecorded tutorials; documentary analysis from students' written work; and quantitative analysis of the students' scores from tests and an examination. The findings show that the conceptual issues that students struggle with during the classroom tutorials, remained unresolved as evidenced from the analyses of the students' written work from the tests and examination. Further research is required to establish the connections between the tutors' abilities for mathematical noticing and their mathematical knowledge for teaching.

Keywords: mathematical noticing, mathematical knowledge, productive struggles, research lesson, productive struggles, quantitative literacy

\section{INTRODUCTION}

This study is part of a larger study whose aims are to research sustainable and practical approaches to tutoring higher education courses, and to support tutors in cultivating mathematically rich learning environments for students by focussing on the normative ways in which tutors engage with classroom practices. By exploring the roles of tutors in mathematical noticing in an undergraduate QL intervention course on the concept of the time value of money, this study will make significant contributions to scholarly debates about tutoring in higher education courses, with a particular focus on classroom discourses. Hardman (2016) and Herrmann (2013) regard higher education as a natural site for learning activities that promote students' deep learning, in addition to creating learning environments where students can engage in robust critical thinking, that stimulates teaching and learning. On the other hand, 
studies show that there is lack of participation by students during tutorials (Rocca 2010) - main reason being the poor quality of student-tutor interactions during tutorials. In addition, research by Entwistle and McCune (2004) suggest that tutors' instructional strategies have a huge influence on how students and tutors interact and learn during tutorials. Research by De Klerk (1997), which explored such interactions between tutors and students showed that the classroom discourse during tutorials was dominated by tutor monologues and short answer questions. In another study by O'Boyle (2010) on tutor-student interactions in higher education courses, the results show that these interactions were similar to those found in schools, where the teacher asked significantly more questions than the students - with students merely providing short answers. The construct of noticing or, in this case, the mathematical [teacher] noticing is not new; it is being used extensively with a focus on pre-university education, that is, in high schools and primary schools (Lee and Choy 2017; Teuscher et al. 2017). Research studies that deal with the construct of mathematical noticing in higher education are few (Breen et al. 2014), and in general studies that focuses on undergraduate mathematics teaching are scarce (Speer at al. 2010). In mathematics classroom, as well as during tutorials, several complex interactions take place between teachers and students, tutors and students, and among students themselves. Sherin and Star $(2011,69)$ concur with this, positing that "a teacher [tutor] is bombarded with a blooming, buzzing confusion of sensory data" during complex classroom settings. During classroom activities, a tutor needs to decide in real time what aspects and concepts in the tutorial he/she needs to attend to, give their own interpretation about what they have attended to, and decide on how to respond to the students' conceptual understandings of the concepts and topic being taught (Van Es 2011).

This study extends previous research that focussed on mathematical teacher noticing, by exploring the roles that that tutors can play during mathematical noticing when tutoring in an undergraduate QL intervention course on the concept of time value of money. For clarity, the QL intervention course is intended to develop the quantitative reasoning skills of first year humanities students who have registered to study Psychology as a major. Students need to use these quantitative reasoning skills to cope with the statistical demands they encounter in their second and third years of the Psychology courses. Moreover, students will require these quantitative skills in the world of work, and as active democratic citizens who are capable of making informed decisions about issues of citizenry.

Based on the research studies on noticing, few research studies have focussed on the role of tutor mathematical noticing in higher education. Whilst there are differences between mathematical noticing as applied by teachers in schools versus mathematical noticing by tutors in higher education courses - both serve the same purpose. Therefore, this study I seeks to 
explore the roles of tutor mathematical noticing during the facilitation stage of a "research tutorial". The study does not focus on the planning and reviewing stages of the research tutorial, but on the facilitation stage. In the context of this study, the term "research tutorial" refers to a tutorial that is jointly planned by both tutors and researchers with the aim of researching on tutoring. One tutor is chosen to facilitate the tutorial, while the others act as observers. After the facilitation stage, the tutors and researchers present their reflections on the tutorial and on students learning in general. This study is guided by the following research questions:

1. What type of common errors and misconceptions were observed by tutors during the tutorial, and in both students' written test and examination on the concept of the time value of money?

2. Did the students perform significantly different in the test and examination on the concept of the time value of money?

\section{THEORETICAL FRAMEWORK}

\section{Tutor noticing}

This study which explores the role of tutors in mathematical noticing is framed within the theoretical construct of noticing. The verb noticing has "an etymology tracing back to Latin words notitia (being known) and notus (known)" (Mason 2011,35). Using everyday language, the term noticing refers to an intentional act of observing or recognising something with an aim of providing accurate accounts of specific instances (Amador 2016; Mason 2011). However, during tutoring, there are different notions of mathematical noticing. I posit that mathematical noticing is a combination of practices aimed improving the tutors' urgency to act during instruction. These practices include but are not limited to "a set of three interrelated skills: attending to children's [students'] strategies, interpreting children's [students'] understandings, and deciding how to respond on the basis of children's [students'] understandings" (Jacobs et al. 2010, 172). In other words, in an instructional setting, tutor noticing is about how tutors attend to particular events, how they make sense of these events, and how they respond to the events in order to address the students' productive struggles during the learning of mathematics, and/or how they align these events to the learning objectives (Choy 2013; Yang and Ricks 2013). Below, I illustrate the relationship between the various stages during tutor noticing, viz. attending, interpreting, and responding (Jacobs et al. 2010). Attending is defined by Mason $(2002,33)$ as a "heightened form of noticing" that identifies what is important and noteworthy about a tutorial session. In this study, attending can be described as the extent to which tutors 
attend to the details of "students' mathematical ideas that surface during instruction" (Stockero $2014,241)$. Interpreting is about how tutors assign meaning and draw connections from the evidence they gathered while researching students' understanding or observed actions [attending]. Responding is about how tutors use the knowledge they have gathered from attending and interpreting as evidence to influence an instructional decision (Teuscher et al. 2017).

\section{Tutor noticing within a research tutorial}

In the introduction, I defined the three stages of a research tutorial, namely: planning - which is done jointly by tutors and lectures, observing and facilitating - which is carried out by tutors, and reviewing - which is jointly done by tutors, lecturers, and observers (these could be other tutors). The observation phase of the research tutorial is meant to gather information about students learning, and not to observe tutoring.

Table 1: Stages involved in tutor noticing during a research tutorial

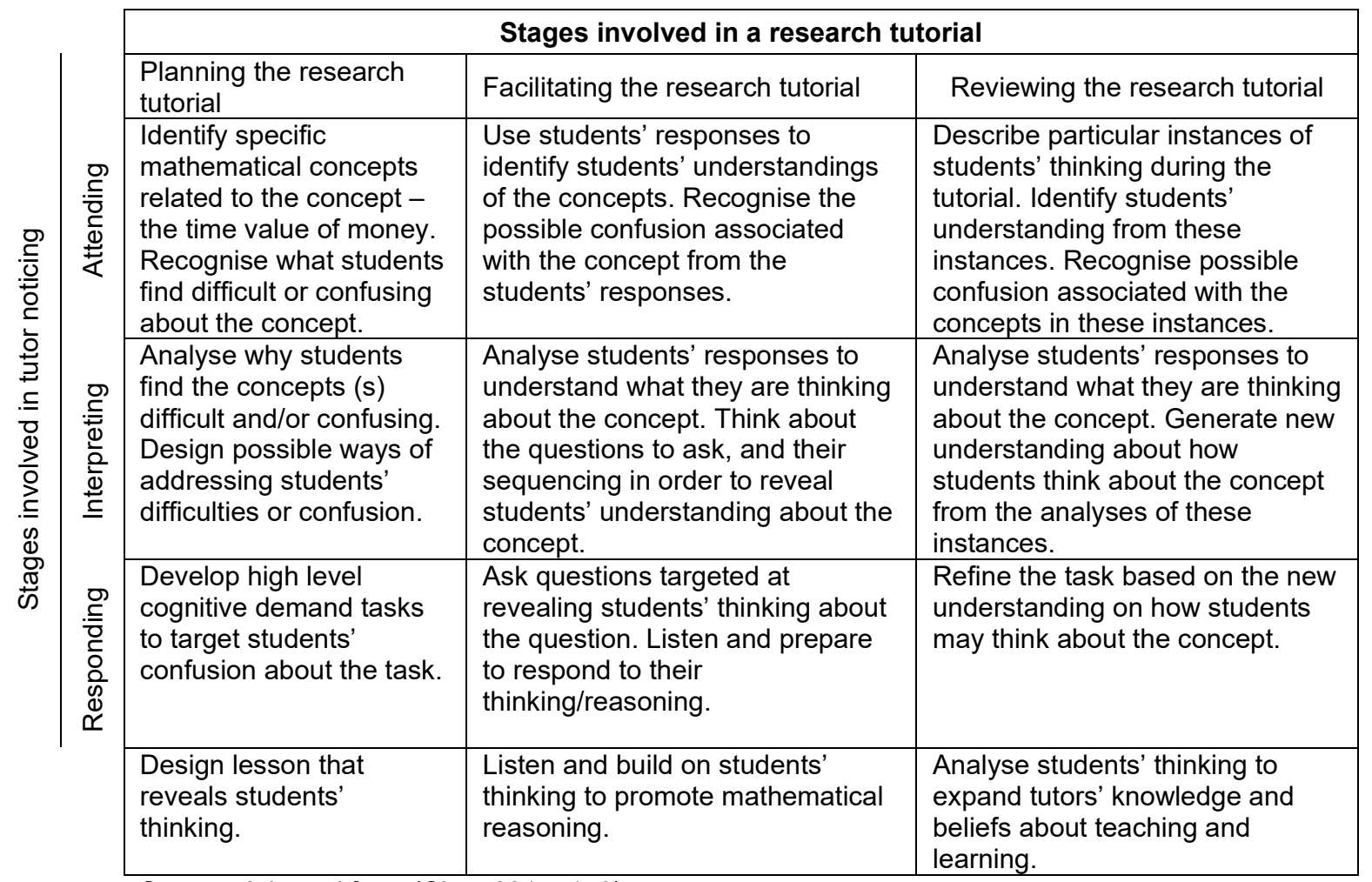

Source: Adapted from (Choy 2015, 178)

Essentially, during the observation stage, the main questions are: did students make progress towards achieving the tutorial objective? Is there evidence to show that students made progress? Is there evidence to show that students did not make progress? And what strategies did the tutor use to support the students to achieve the learning goals of the tutorials (Santagata 2011). At 
each one of the three stages, noticing take place differently - see Table 1 . In this study, the focus is on what takes place during the facilitating research tutorial stage.

\section{METHODOLOGY}

\section{Participants}

Three hundred and six undergraduate students from the Humanities Faculty enrolled in a QL intervention course participated in this study, and gave permission for their test and examination marks to be part of the data sources. From these three hundred and six students, forty were part of two tutorial groups - twenty in each group, who volunteered to be part of the two audiorecorded tutorials. The two tutorial groups that participated in the audio-recordings were facilitated by tutors who had strong mathematics background: they were doctoral students in financial mathematics and electrical engineering. In addition, the sample also consisted of a research assistant - who acted as an observer.

\section{Context and data collection}

In this study, the research methodology is used is the lesson study. The lesson study possesses certain key characteristics that are critical for the effective professional development of tutors: "it is site-based, practice oriented, focused on students learning, collaboration-based, and research oriented" (Murata 2011, 2). Lesson study develops the tutors' interest and desire to deepen students' understandings about specific mathematical concepts. Typically, the lesson study is enacted through the stages of the research tutorial already outlined in the previous section. When planning the research tutorial, tutors and researchers would have in mind three "case students"; these were students who were either experiencing learning difficulties, or high achievers, or middle achievers in mathematics (Dudley 2014). During the planning of the research tutorial, tutors and researchers would think about how each one of these three students would actively participate in the different learning activities of the tutorial. Both the tutors and researchers would arrive at some consensus on how to respond to each one the case students. Such predictions play an important role in the research tutorials. After planning the research tutorials, one tutor would facilitate the tutorial, while the research assistant would observe. To be clear, the observer would be focusing on the student learning in the context of the content being taught, and not on how the tutor facilitated the research tutorial. The facilitation of the research tutorial was audio-recorded. Post-observation and facilitating reflections focus on discussing the "learning of the case pupils [students] one after the other before discussing teaching [tutoring]" (Dudley 2014, 11). In addition, students' achievements, in terms of marks, from the test and the examination were quantitatively analysed and compared. 


\section{FINDINGS AND DISCUSSIONS}

In this section, I analyse two vignettes from two tutors of the research tutorial. For the sake of anonymity, the two tutors are referred to as Tom and Tami. Each one of them facilitated a tutorial comprising of twenty students. The tutorial question, whose objective is for the students to solve real world questions on the time value of money in an everyday real context, is given below. This particular question is rated at the level of comprehension in terms of Bloom's taxonomy of educational categorisation (Adams 2015; Bloom et al. 1956; Ramirez 2017). At the level of comprehension, students are required to build "cognitive categories and [to recognise] relationships between them" (Ramirez 2017, 148). For example, students are expected to recognise and draw the relationships between the base year, inflation, actual values, and real values. In order to unpack the latter, students can use concept maps.

\section{Tutorial question}

"The North West Province of South Africa recorded the highest food inflation of 23.4\% in 2008. Source: Adapted from An analysis of drivers of inflation in KwaZulu-Natal, by Cosmas Hamadziripi, August 2008. Use the food inflation rate for North West Province to answer the following questions: In a town in North West Province a litre of milk cost R7.50 in June 2007 and R9.26 in June 2008. Using 2007 as the base year, compare the price of a litre of milk in 2007 and 2008 in real terms. In other words, was the increase in the milk cost between 2007 and 2008 below, in line with, or above inflation?"

\section{Vignette of Tami's tutorial}

Tami: "I have moved from 2007 to 2008 , my price changed from 7.5 to 9.26 so what does that mean?" (Whispering to student). "Are you confused?"

Students: "Yes" (in chorus).

Tami: "This 9.26 already includes inflation because when you move from 7.5 to 9.26. You need to find the real price; how do I find the real price?"

Student: "By dividing."

Tami: "So this I divide by what? Because, remember, I am moving backwards."

Student: "The growth factor, which is 1.234."

Tami: "What did you get?"

Student: "I'm confused, because I thought that to get the real value, you must also multiply this by the growth factor."

Tami: "Do you remember when I said that the base here is used for comparison?"

Student: "Hmm."

Tami: "Okay, so if my actual value was 9.26 with inflation, how do I get to this point? I have to move backwards, so you divide by the grow factor." 
Whilst attending to the students' mathematical thinking, Tami notices that one of the students was confused, and immediately asks the student: "Are you confused?" When the students acknowledge that they are confused, Tami starts to give her interpretation about what mathematical conceptions were proving to pose a challenge to the students. She thus focusses on the difference between R9.26 and R7.50 - clearly emphasizing that the value of R9.26 includes inflation. Tami continues to focus "on key features relevant to monitoring student understanding" (Miller 2011, 51), by asking students how to find the real price, given the actual price. By anticipating the students' difficult point - calculating the real value for R9.26 (Lee and Choy 2017), Tami asks: "So this I divide by what? Because, remember, I am moving backwards". Using the year 2007 as the base year, it is clear that the student should divide the 2008 milk price by the inflation growth factor. The students are failing to understand the applicable rule, which says that, if the base year is the year before, one divides the price of milk of the year ahead by the inflation growth factor. The reverse process applies, in other words, one multiplies going forward. In responding to the students' challenges, the tutor makes a realtime instructional decision (Jacobs et al. 2010), when Tami asks the question: "Do you remember when I said that the base here is used for comparison?" These types of questions posed by Tami encourage students to focus on her previous interactions with students, and on their learning, in addition to recalling details and supporting evidence of these learning moments (McDuffie et al. 2014; Santagata 2011).

\section{Vignette of Tom's tutorial}

Tom: "Therefore, to remove the inflation it is 9.26 divided by this growth factor, and that gives you this, the real value, so do you get what I am trying to say? Hence, you are trying to undo the percentage increase."

Students: Nodding (show that they agree).

Tom: "So what is the growth factor?"

Student: "Can you show us how to calculate the growth factor?"

Tom: "This one? It is 1 plus r over 100, which is 1 plus 23.4 over 100."

Student D: "We cannot see."

Tom: "So you said the group factor is equal to 1 plus r over 100" (Tom writes on the board). Students start laughing.

Students: "Yes."

Tom: "So do you get what is happening? This is the growth factor that you use when dividing R9.26. Does this make sense?"

Tom experienced similar challenges to Tami - he also had to attend to the students' 
mathematical thinking or the main mathematical concepts of the tutorial (Yang and Ricks 2012). These included undoing inflation from an actual price of R9.26 in order to get to the real value, and the interpretation thereof. He asks the students: "so do get what I am trying to say?" The students nod to show that they agree. However, it appears that Tom is still not convinced and thus seeks clarification from the students - "so what is the growth factor?" A student asks Tom to show them how to calculate the growth factor. To respond to the student's question, Tom decides to show the students how the growth factor was calculated. Tom assesses his own explanation to what he noticed about the students' mathematical thinking (Wager 2014), and his interpretation of the students' strategies, based on evidence gathered from their conceptual understandings (Jacobs et al. 2010; Turner et al. 2012). After engaging with the students' mathematical thinking, and probing students' understanding of the mathematical concept, Tom intentionally asked the questions: "So do you get what is happening? Does this make sense?" Throughout Tom's interactions with the students, the process of "noticing is predicated on solidly linking the practices of attending, interpreting, and deciding" (Thomas et al. 2015, 297).

\section{Analysis of a test and an examination question}

In this section, a summary of the descriptive statistics of the students' performance on the test and the examination is given. Examples of selected students' written solutions are given to illustrate some of the students' mathematical thinking when solving the questions on the time value of money. The discussions on the students' written solutions were general, and do not necessarily refer to the solutions of the students' written work illustrated.

\section{Test question: What's up with the price of bread? | Voice of the Cape}

Source: https://www.vocfm.co.za - Nomsa Vumazonke buys two loaves of bread every day. She lives in Philippi with her three children and four grandchildren, and after making sandwiches for them, says there is nothing left for her to eat. "Bread is too expensive. It's very hard. I have to buy bread for my children," she says. The table below shows the actual price of white bread from January 2012 to January 2016.

\begin{tabular}{|l|l|l|l|l|l|l|l|l|l|}
\hline \multicolumn{1}{|c|}{ Year } & $\mathbf{2 0 1 2}$ & & $\mathbf{2 0 1 3}$ & & $\mathbf{2 0 1 4}$ & & $\mathbf{2 0 1 5}$ & $\mathbf{2 0 1 6}$ \\
\hline${ }^{*}$ Inflation rate (\%) & & 5.62 & & 5.76 & & 4.40 & & 4.58 & \\
\hline White bread actual price (rands) & 8.99 & & 9.73 & & 10.49 & & 11.43 & & 12.25 \\
\hline
\end{tabular}

${ }^{*}$ Note for example, that the inflation rate from January 2012 to January 2013 is $5.62 \%$

Question 4d. Using 2013 as the base year, do a calculation and explain whether the price of white bread increased in real terms between January 2013 and January 2014. 
Table 2 shows how the students performed in Question 4d of the test - the question had a total of 2 scores. Slightly more than half of the students (55\%) scored full marks on the question.

Table 2: Distribution of scores for the assessment question

\begin{tabular}{|l|c|c|c|}
\hline \multicolumn{1}{|c|}{ Question } & Scores & $\begin{array}{c}\text { Frequency of } \\
\text { scores }\end{array}$ & $\begin{array}{c}\text { Percentage } \\
\text { frequency }\end{array}$ \\
\hline \multirow{3}{*}{$\begin{array}{l}\text { Using 2013 as the base year, do a calculation } \\
\text { and explain whether the price of white bread } \\
\text { increased in real terms between January 2013 } \\
\text { and January 2014. }\end{array}$} & 2 & 168 & 55 \\
\cline { 2 - 4 } & 1.5 & 55 & 18 \\
\cline { 2 - 4 } & 0.5 & 43 & 15 \\
\hline Total & 0 & 13 & 5 \\
\hline
\end{tabular}

Figure 1 shows an example of a student' written solution - the aim of this example is to show one of the misconception that students had on this question, which happened to be a common error that tutors attempted to resolve during the tutorials.

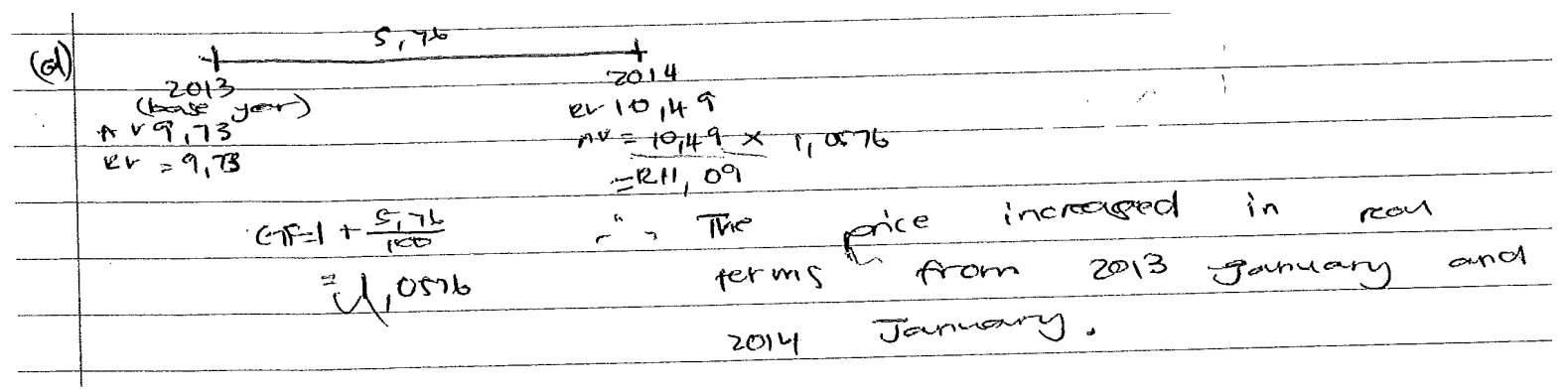

Figure 1: Student's solution on the test question

At the comprehension level of this question, students demonstrate an accurate basic understanding of the concept of the time value of money. Students translate the context into a mathematical problem - the use of the timeline as a concrete representation facilitates personalised processing of the mathematical concepts (Adams 2015). Using 2013 as a base, a common conceptual error made by students is that they multiply the 2014 price by the growth factor, instead of dividing by the growth factor. For example, Figure 1 represents the latter the student drew the correct timeline, had the correct calculation of the growth factor, but made a conceptual error of multiplying the 2014 value by the growth factor instead of dividing. This conceptual challenge was also experienced by the tutors during tutorials; the observer posits that: "the real and actual terms calculations were still very confusing to my tutorials groups". 


\section{Examination question: Gold producers dig in heels over wage increases}

Source: The Guardian, Wednesday $21^{\text {st }}$ August 2013 - South African gold mining wage dispute remains at an impasse. The current entry level wage of miners is R5 000 a month. The year-onyear inflation rates from July 2011 to July 2013 are shown below.

\begin{tabular}{|l|l|l|l|l|c|}
\hline \multicolumn{1}{|c|}{ Year } & July $\mathbf{2 0 1 1}$ & & July 2012 & & July 2013 \\
\hline${ }^{*}$ Inflation rate & & $5.71 \%$ & & $6.30 \%$ & \\
\hline Actual entry-level wage of miners & & & & & 5000 \\
\hline
\end{tabular}

g(i) Calculate the 2013 entry-level wage of R5 000 in real terms, using 2011 as the base year?

g(ii) The actual entry-level wage in 2011 was R4 100. Use your answer in (a) above to explain whether or not the buying power of a miner who remained on an entry-level wage increased from 2011 and 2013.

g(iii) Did the entry-level wages of mine workers keep up with inflation from 2011 to 2013 ?

This examination question consists of three sub-questions: Question g(i), which is analysed on its own, and Questions g(ii) and g(iii) are combined. Sub-question g(i) has a total score of 2, and g(ii) and g(iii) had a combined score of 2. In terms of cognitive levels, g(i) is at the comprehension level (see the test question analysis), while g(ii) and g(iii) combined are at the application level (Adams 2015; Ramirez 2017). At the application level, more complex skills are expected; these include the interpretation of results confined to comparing the entry-level real wages of 2011 and 2013.

Table 3 shows the distribution of the students' scores in the examination sub-questions on the time value of money. Students performed better on Question g(i), as evidenced by the distribution of scores -63 per cent of the students scored at least 75 per cent in this question. This was expected, since g(i) is categorized at the level of comprehension in terms of Bloom's taxonomy. In contrast, 33 per cent of the students scored at least 75 per cent in Sub-questions $(\mathrm{g}(\mathrm{ii})+\mathrm{g}(\mathrm{iii}))-$ the reason was that the sub-questions were set at the application level of Bloom's taxonomy.

Table 3: Distribution of scores for items $g(i)$ and $(g(i i)+g(i i i))$ of the examination question

\begin{tabular}{|c|c|c|c|}
\hline Question & Scores & $\begin{array}{c}\text { Frequency of } \\
\text { scores }\end{array}$ & $\begin{array}{c}\text { Percentage } \\
\text { frequency }\end{array}$ \\
\hline & 2 & 185 & 60 \\
\cline { 2 - 4 } & 1.5 & 8 & 3 \\
\cline { 2 - 4 } $\begin{array}{c}\text { g(i) Calculate the 2013 entry-level wage of } \\
\text { R5 000 in real terms, using 2011 as } \\
\text { the base year? }\end{array}$ & 1 & 65 & 21 \\
\cline { 2 - 4 } & 0.5 & 20 & 7 \\
\hline Total & 0 & 28 & 9 \\
\hline
\end{tabular}




\begin{tabular}{|c|c|c|c|}
\hline Question & Scores & $\begin{array}{c}\text { Frequency of } \\
\text { scores }\end{array}$ & $\begin{array}{c}\text { Percentage } \\
\text { frequency }\end{array}$ \\
\hline g(ii) The actual entry-level wage in 2011 \\
was R4 100. Use your answer in g(i) \\
$\begin{array}{l}\text { above to explain whether or not the } \\
\text { buying power of a miner who } \\
\text { remained on an entry-level wage } \\
\text { increased from 2011 and 2013. }\end{array}$ & 2 & 42 & 14 \\
\cline { 2 - 4 } $\begin{array}{l}\text { g(iii) Did the entry-level wages of mine } \\
\text { workers keep up with inflation from } \\
\text { 2011 to 2013? }\end{array}$ & 1.5 & 59 & 19 \\
\cline { 2 - 4 } & 0.5 & 84 & 27 \\
\hline Total & & 46 & 25 \\
\hline
\end{tabular}

Figure 2 illustrates a solution of a student on Sub-questions g(i), g(ii), and g(iii). From g(i), it is evident that the student had the correct timeline; however, the student did not get the operations right. Using 2011 as the base year, instead of dividing by the two growth factors, the student multiplied by the two growth factors. During tutorial observations, the research assistant asserts that: "at this stage many students could successfully draw the number timeline, but were still making errors when calculating real values [real wages]".

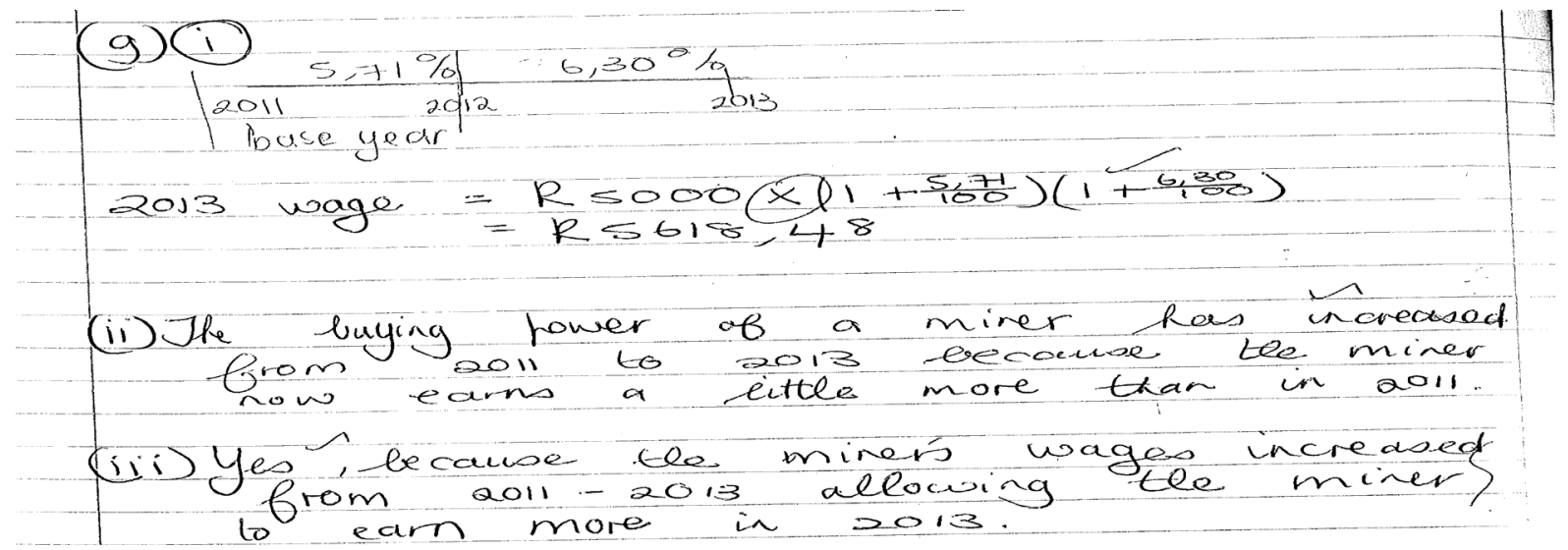

Figure 2: Student's solution to the examination question

The aim of the sub-questions was to test students' interpretations, on the notions of whether the miners' buying power had increased/decreased, and whether the increase/decrease was in line with inflation. These were more complex mathematical conceptions, which presented numerous challenges to the students. Similar challenges were also experienced by the tutors during tutorials; Tom posits: "I had to explain the idea of increase below and above the line of inflation from every question". The students' written solutions of the test and examination show that there are conceptual challenges with regard to the time value of money, which students experienced during tutorials and which persisted during the written test and the examination. 


\section{Quantitative analysis of the assessment and exam marks}

The aim of conducting the quantitative analysis was to test whether there were any significant differences between the test scores (with regard to Question 4d) based on the 306 students who had complete and valid data, and the examination marks on certain questions (Questions $g(i)$, $\mathrm{g}(\mathrm{ii})$, and $\mathrm{g}(\mathrm{iii})$ ) testing the time value of money concept. In addition, a comparison was carried out between two examination questions. These results indicate that the mean of Question $4 \mathrm{~d}$ is not statistically significantly different from the mean of Question $g(i),(1.53$ vs. $1.49 ; \mathrm{t}=0.7361$, $\mathrm{p}=0.4623)$. When Question $4 \mathrm{~d}$ was compared to the combined mark of $(\mathrm{g}(\mathrm{ii})+\mathrm{g}(\mathrm{iii}))$, the results indicate that the mean of Question $4 \mathrm{~d}$ is statistically significantly different from the mean of $(\mathrm{g}(\mathrm{ii})+\mathrm{g}(\mathrm{iii})),(\mathrm{t}=13.0226, \mathrm{p}<0.001)$. The mean of Question $4 \mathrm{~d}$ is higher than $(\mathrm{g}(\mathrm{ii})+\mathrm{g}(\mathrm{iii}))$, (1.53 vs 0.92). This means that the students performed better in Question 4d. A comparison between $g(\mathrm{i})$ and $(\mathrm{g}(\mathrm{ii})+\mathrm{g}(\mathrm{iii}))$ show that the mean of Question $\mathrm{g}(\mathrm{i})$ is statistically significantly different from the mean of $(\mathrm{g}(\mathrm{ii})+\mathrm{g}(\mathrm{iii})),(\mathrm{t}=12.379, \mathrm{p}<0.001)$. The mean of Question $\mathrm{g}(\mathrm{i})$ is higher than $(\mathrm{g}(\mathrm{ii})+\mathrm{g}(\mathrm{iii}))$, (1.49 vs 0.92$)-$ meaning that the student performed better in response to Question $g(\mathrm{i})$ than Question $(\mathrm{g}(\mathrm{ii})+\mathrm{g}(\mathrm{iii}))$. The results of this analysis show that students scored fewer points on the application question, namely, $(g(i i)+g(i i i))$ than on the comprehension questions. In light of this finding, it is clear that tutor development focussing on mathematical noticing needs to dedicate more time to seeking approaches that deepen students' mathematical thinking on application questions.

\section{CONCLUSION}

This study has provided evidence that shows that tutors, despite being inexperienced, are capable of noticing students' key mathematical thinking, and engagement during tutorials. Much of the work on mathematical noticing has focussed on school teachers in both primary and high schools, with less attention given to noticing that takes place during tutoring. Among researchers in mathematics education, mathematical noticing is conceptualised in various ways; however, there is a general consensus that it influences the quality of mathematics instruction (Jacobs et al. 2010; Lee 2018). Part of the findings of the study have shown that tutors accurately identified mathematical concepts that were challenging to the students - the assumption here is that the tutor noticing that did take place is evidence-driven. Some of the misconceptions and errors identified by tutors during tutorials were observed in the students' written solutions in response to both the test and the examination. Since this study is about researching sustainable and practical approaches to tutoring, further research is required to establish the connections between the tutors' abilities for mathematical noticing and their mathematical knowledge for teaching. 
In addition, since noticing plays a critical role during tutoring, there is a need to explore ways in which the professional development of tutors with a focus on classroom practices can help tutors to improve their mathematical noticing during their interactions and engagement with students during tutoring. The existing literature suggests "that tutors lack training in tutoring and may lack clarity as to the purpose and boundaries of the role" (McFarlane 2016, 77), this challenge can be addressed through just-in-time job-embedded professional development of tutors. In other words, the training of tutors needs to address the tutors' contextual needs on how to improve their instruction as well as students' learning.

\section{REFERENCES}

Adams, Nancy E. 2015. Bloom's taxonomy of cognitive learning objectives. Journal of the Medical Library Association 103(3): 152-153. http://doi.org/10.3163/1536-5050.103.3.010

Amador, Julie. 2016. Professional noticing practices of novice mathematics teacher educators. International Journal of Science and Mathematics Education 14(1): 217-241.

Bloom, Benjamin S. (Ed.), M. D. Englehart, E. J. Furst, W. Hill and D. R. Krathwohl. 1956. Taxonomy of educational objectives: The classification of educational goals. Handbook I: Cognitive domain. Longman Publishing Group.

Breen, Sinead., Aisling McCluskey, Maria Meehan, Julie O'Donovan and Ann O'Shea. 2014. A year of engaging with the discipline of noticing: Five mathematics lecturers' reflections. Teaching in Higher Education 19(3): 289-300.

Choy, Ban H. 2013. Productive mathematical noticing: What it is and why it matters. In Mathematics education: Yesterday, today, and tomorrow, ed. V. Steinle, L. Ball and Bardini. Proceedings of the 36th annual conference of the Mathematics Education Research Group of Australasia. Melbourne, VIC: MERGA.

Choy, Ban H. 2015. The FOCUS framework: Snapshots of mathematics teacher noticing. Unpublished doctoral dissertation. Newland: University of Auckland.

De Klerk, Vivian. 1997. Interaction patterns in university education. In Oral discourse and education, 207-216. Springer, Dordrecht.

Dudley, Paul. (Ed.). 2014. Lesson study: Professional learning for our time. Routledge.

Entwistle, Noel and Velda McCune. 2004. The conceptual bases of study strategy inventories. Educational Psychology Review 16(4): 325-345.

Hardman, Jan. 2016. Tutor-student interaction in seminar teaching: Implications for professional development. Active Learning in Higher Education 17(1): 63-76.

Herrmann, Kim J. 2013. The impact of cooperative learning on student engagement: Results from an intervention. Active Learning in Higher Education 14(3): 175-187.

Jacobs, Victoria R., Lisa C. Lamb and Randolph A. Philipp. 2010. Professional noticing of children's mathematical thinking. Journal for Research in Mathematics Education 41(2): 169-202.

Lee, Mi. Y. 2018. Further investigation into the quality of teachers' noticing expertise: A proposed framework for evaluating teachers' models of students' mathematical thinking. Eurasia Journal of Mathematics, Science and Technology Education 14(11): em1570. https://doi.org/ 10.29333/ejmste/92019

Lee, Mi. Y. and Ban H. Choy. 2017. Mathematical teacher noticing: The key to learning from lesson study. In Teacher noticing: Bridging and broadening perspectives, contexts, and frameworks, ed. E. O. Schack, 121-140. Springer, Cham. 
Mason, John. 2002. Researching your own practice: The discipline of noticing. New York, NY: Routledge/Falmer.

Mason, John. 2011. Noticing: Roots and branches. In Mathematics teacher noticing: Seeing through teachers' eyes, ed. M. G. Sherin, V. Jacobs and R. Phillip, 35-50. New York. Routledge.

McDuffie, Amy R., Mary Q. Foote, Catherine Bolson, Erin E. Turner, Julia M. Aguirre, Tonya G. Bartell, ... and Tonia Land. 2014. Using video analysis to support prospective K-8 teachers' noticing of students' multiple mathematical knowledge bases. Journal of Mathematics Teacher Education 17(3): 245-270.

McFarlane, Kathryn J. 2016. Tutoring the tutors: Supporting effective personal tutoring. Active Learning in Higher Education 17(1): 77-88.

Miller, Kevin F. 2011. Situation awareness in teaching: What educators can learn from video-based research in other fields? In Mathematics teacher noticing: Seeing through teachers' eyes, ed. M. G. Sherin, V. R. Jacobs and R. A. Philipp, 51-65. New York, NY: Routledge.

Murata, Aki. 2011. Introduction: Conceptual overview of lesson study. In Lesson study research and practice in mathematics education, ed. L. C. Hart, A. S. Alston, A. Murata, 1-12. Springer, Dordrecht.

O'Boyle, Aisling. 2010. The dialogic construction of knowledge in university classroom talk: A corpus of spoken academic discourse. Unpublished PhD Thesis, Queen's University, Belfast, Kingstone, $\mathrm{ON}$.

Ramirez, Tatyana V. 2017. On pedagogy of personality assessment: Application of Bloom's Taxonomy of Educational Objectives. Journal of Personality Assessment 99(2): 146-152.

Rocca, Kelly A. 2010. Student participation in the college classroom: An extended multidisciplinary literature review. Communication Education 59(2): 185-213.

Santagata, Rossella. 2011. From teacher noticing to a framework for analysing and improving classroom lessons. In Mathematics teacher noticing: Seeing through teachers' eyes, ed. M. G. Sherin, V. R. Jacobs and R. A. Philipp, 152-168. New York, NY: Routledge.

Sherin, Bruce and Jon R. Star. 2011. Reflections on the study of teacher noticing. In Mathematics teacher noticing: Seeing through teachers' eyes, ed. M. G. Sherin, V. R. Jacobs and R. A. Philipp, 66-78. New York, NY: Routledge.

Speer, Natasha M., John P Smith III and Aladar Horvath. 2010. Collegiate mathematics teaching: An unexamined practice. The Journal of Mathematical Behavior 29(2): 99-114.

Stockero, Shari L. 2014. Transitions in prospective mathematics teacher noticing. In Research trends in mathematics teacher education, 239-259. Springer, Cham.

Teuscher, Dawn, Keith R. Leatham and Blake E. Peterson. 2017. From a framework to a lens: Learning to notice student mathematical thinking. In Teacher noticing: Bridging and broadening perspectives, contexts, and frameworks, ed. E. O. Schack et al., 31-48. Springer, Cham.

Thomas, Jonathan N., Sara Eisenhardt, Molly H. Fisher, Edna O. Schack, Janet Tassell and Margaret Yoder. 2015. Professional noticing: Developing responsive mathematics teaching. Teaching Children Mathematics 21(5): 294-303.

Turner, Erin E., Corey Drake, Amy R. McDuffie, Julia Aguirre, Tonya G. and Mary Q. Foote. 2012. Promoting equity in mathematics teacher preparation: A framework for advancing teacher learning of children's multiple mathematics knowledge bases. Journal of Mathematics Teacher Education 15(1): 67-82.

Van Es, Elizabeth A. 2011. A framework for learning to notice student thinking. In Mathematics teacher noticing: Seeing through teachers' eyes, ed. M. G. Sherin, V. R. Jacobs and R. A. Philipp, 134151. New York, NY: Routledge.

Wager, Anita A. 2014. Noticing children's participation: Insights into teacher positionality toward equitable mathematics pedagogy. Journal for Research in Mathematics Education 45(3): 312350. 
Yang, Yudong and Thomas E. Ricks. 2012. How crucial incidents analysis support Chinese lesson study. International Journal for Lesson and Learning Studies 1(1): 41-48.

Yang, Yudong and Thomas E. Ricks. 2013. Chinese lesson study: Developing classroom instruction through collaborations in school-based teaching research group activities. In How Chinese teach mathematics and improve teaching, ed. Y. Li and R. Huang, 51-65. New York: Routledge. 